\title{
Gender differences in COPD: are women more susceptible to smoking effects than men?
}

\author{
Inga-Cecilie Sørheim, ${ }^{1}$ Ane Johannessen, ${ }^{2}$ Amund Gulsvik, ${ }^{1}$ Per S Bakke, ${ }^{3}$ \\ Edwin K Silverman, ${ }^{4}$ Dawn L DeMeo ${ }^{4}$
}

\begin{abstract}
- Additional figures and tables are published online only. To view these file please visit the journal online (http://thorax.bmj. com).

${ }^{1}$ Institute of Medicine, University of Bergen, Bergen, Norway

${ }^{2}$ Centre for Clinical Research, Haukeland University Hospital, Bergen, Norway ${ }^{3}$ Department of Thoracic Medicine, Haukeland University Hospital, Bergen, Norway ${ }^{4}$ Channing Laboratory and Pulmonary and Critical Care Division, Brigham and Women's Hospital, Harvard Medical School, Boston, Massachusetts, USA
\end{abstract}

\section{Correspondence to}

Dawn L DeMeo, Channing Laboratory, 181 Longwood Avenue, Boston, MA 02115, USA; dawn.demeo@channing. harvard.edu

Received 18 June 2009 Accepted 28 March 2010

\section{ABSTRACT}

Background The number of female smokers developing chronic obstructive pulmonary disease (COPD) is rapidly increasing, but whether or not there exists a differential susceptibility by gender remains controversial.

Methods How smoking behaviour and subsequent lung function reduction differed by gender was examined in a study including 954 subjects with COPD and 955 subjects without COPD. The study focused on two subgroups: subjects with COPD $<60$ years of age (earlyonset group, $n=316$ ) and subjects with COPD with $<20$ pack-years of smoking (low exposure group, $n=241$ ).

Results In the low exposure group, female subjects with COPD had lower forced expiratory volume in $1 \mathrm{~s}\left(\mathrm{FEV}_{1}\right) \%$ predicted $(48.7 \%$ vs $55.8 \%, p=0.001)$ and more severe disease $(50.4 \%$ vs $35.6 \%, p=0.020$, in GOLD (Global Initiative for Chronic Obstructive Lung Disease) stage 3 and 4) than male subjects with COPD. Females also had lower $\mathrm{FEV}_{1} \%$ predicted $(50.6 \%$ vs $56.0 \%, \mathrm{p}=0.006)$ and more severe COPD $(41.7 \%$ vs $31.1 \%$ in GOLD stage 3 and $4, p=0.050$ ) in the early-onset group. Using multivariate regression, female gender was associated with $5.7 \%$ lower $\mathrm{FEV}_{1} \%$ predicted in the low exposure group ( $p=0.012$ ) and a similar trend was observed in the early-onset group ( $p=0.057)$. The number of pack-years was not significantly associated with lung function in female subjects with COPD in this study, and the dose-response relationship between smoking and lung function differed by gender at lower levels of smoking exposure. Interaction analysis suggested that the effect of smoking on lung function might be different by gender ( $p=0.027$ in all subjects with COPD).

Conclusions Female gender was associated with lung function reduction and more severe disease in subjects with COPD with early onset of disease or low smoking exposure. The findings may suggest a gender difference in susceptibility to the lung-damaging effects of cigarette smoking, but alternative explanations should be considered.

For many years chronic obstructive pulmonary disease (COPD) was considered a disease of men, with higher global prevalence in men than in women. Today the number of women with COPD is rapidly increasing, and for the first time the number of deaths from COPD in women have surpassed those in men in the USA. ${ }^{1}$

This development has been attributed to changes in the historical differences in smoking behaviour in men and women. Recent research has suggested that women may be more susceptible to the lungdamaging effects of smoking, but the findings are inconsistent. Several studies have indicated an increased female susceptibility to smoking-related decline in lung function, ${ }^{2-7}$ whereas other studies have suggested an opposite gender effect. ${ }^{8}$ Whether or not there exists a differential susceptibility by gender remains controversial, and little is known about the mechanisms and implications of a possible gender difference in COPD.

Male-female differences are often divided into sex-related (biological) and gender-related (environmental and socio-cultural) differences. ${ }^{9}$ In this manuscript, we use the term gender to refer to both sex- and gender-related factors. The demonstration of gender differences can be challenging, especially in cross-sectional case-control studies. Often the female representation among COPD cases has been low, and women have typically smoked significantly less than men, both of which can complicate the comparison. We hypothesised that a differential susceptibility to COPD by gender would be easier to demonstrate if we explored subgroups of the total study sample. If female smokers are more susceptible to the lung-damaging effects of cigarettes than men, they will probably experience reduced lung function and COPD at a lower level of exposure and/or at an earlier age than men.

Our main objective was to examine how smoking behaviour and subsequent lung function reduction and COPD severity differed by gender in a large COPD study, focusing mainly on subgroups of COPD subjects with early onset of disease or low smoking exposure.

Some of the results have been previously reported in the form of an abstract. ${ }^{10}$

\section{METHODS}

\section{Study population}

A large study of COPD was performed at Haukeland University Hospital (Bergen, Norway) in 2003-2005. ${ }^{11}$ Nine hundred and fifty-four subjects with COPD (cases) and 955 subjects without COPD (controls) were recruited from three different sources: the general population (186 cases and 734 controls), the Haukeland University Hospital COPD Registry (697 cases) and volunteers (71 cases and 221 controls). The general population sample consisted of previous participants in two general population cohort studies, ${ }^{12}{ }^{13}$ the COPD registry consisted of patients with a COPD or emphysema diagnosis in 1997-2005, and the volunteers were people who contacted the study staff and expressed willingness to participate

All study participants were Caucasians $\geq 40$ years old, current or ex-smokers with $\geq 2.5$ pack-years, and without severe $\alpha-1$ antitrypsin deficiency (as determined by isoelectric focusing). Subjects with COPD were required to have postbronchodilator 
(post-BD) forced expiratory volume in $1 \mathrm{~s}\left(\mathrm{FEV}_{1}\right) /$ forced vital capacity $(\mathrm{FVC})<0.7$ and $\mathrm{FEV}_{1} \%$ predicted $<80 \%$. Subjects without $\mathrm{COPD}$ were required to have post-BD $\mathrm{FEV}_{1} / \mathrm{FVC} \geq 0.7$ and $\mathrm{FEV}_{1} \%$ predicted $\geq 80 \%$.

Spirometry was performed with a Vitalograph Gold Standard Plus 2160 according to American Thoracic Society standards, ${ }^{14}$ before and $30 \mathrm{~min}$ after bronchodilation with $0.4 \mathrm{mg}$ of salbutamol. Predicted values of $\mathrm{FEV}_{1}$ and FVC were calculated using equations from a Norwegian reference population. ${ }^{15}$ Bronchodilator response was defined as percentage change from prebronchodilator values $(100 \times$ (post-BD FEV 1 - pre-BD FEV 1 )/ pre-BD $\mathrm{FEV}_{1}$ ).

One pack-year was defined as smoking an average of 20 cigarettes a day for 1 year. Educational level was classified into three categories: (1) 9 year compulsory school; (2) continuation school, lower secondary school, upper secondary school or technical school; (3) college or university. ${ }^{16}$ Self-reported asthma was defined by an affirmative answer to the following question: 'Have you ever been told by a doctor that you have asthma?' Occupational exposure was defined as an affirmative answer to the question: 'Did you ever work in a place with a lot of dust or gas in the air?'

The Regional Committee for Medical Research Ethics (REK Vest), the Norwegian Data Inspectorate and the Norwegian Department of Health approved the case-control study. Written informed consent was obtained from all participants.

\section{Statistical analysis}

Statistical analyses were performed using Stata 10.0 (StataCorp, College Station, Texas, USA). Statistical comparisons of characteristics were done using $t$ tests for continuous variables, $\chi^{2}$ tests for categorical variables and Wilcoxon tests for medians.

We analysed $\mathrm{FEV}_{1}$ using multivariate linear regression models. Covariates for model inclusion were selected a priori. Analyses of $\mathrm{FEV}_{1}$ in millilitres were adjusted for age, height, pack-years of smoking, self-reported asthma history and educational level. Educational level was included as a marker of socio-economic status. ${ }^{17} 18$ Analyses of $\mathrm{FEV}_{1} \%$ predicted were adjusted for packyears, self-reported asthma history and educational level (the prediction equations are sex, age and height adjusted). The specific interaction between gender and smoking was tested a priori based on a predefined hypothesis: is the effect of smoking on lung function different by gender?

Gender-specific estimates for each pack-year's effect on $\mathrm{FEV}_{1} \%$ predicted were obtained using the command lincom in Stata, after running models that included a gender $\times$ pack-years interaction term. Lincom is a postestimation technique, computing linear combinations of coefficients. To find the combined coefficient for pack-years for each gender, we used the lincom command: lincom pack-years + gender*pack-years. For all subjects with or without COPD, each pack-year's effect on $\mathrm{FEV}_{1} \%$ predicted was obtained using models without a gender $\times$ pack-years interaction term.

We performed analyses in two predefined subgroups. The early-onset group consisted of all subjects with COPD $<60$ years of age at the time of study $(n=316,33 \%$ of all subjects with COPD). The low exposure group consisted of all subjects with COPD with a smoking history of $<20$ pack-years $(n=241,25 \%$ of all subjects with COPD). Eighty-eight subjects ( $9 \%$ of all subjects with COPD) were present in both the early-onset and low exposure subgroups-of these, $47(53.4 \%)$ were women.

All $p$ values were two-sided and values $<0.05$ were considered statistically significant.

\section{RESULTS}

\section{Characteristics of study subjects}

The total study sample consisted of 954 subjects with COPD and 955 subjects without COPD; $38.9 \%$ of the subjects with COPD and $49.8 \%$ of the subjects without COPD were women. The characteristics of study participants by gender are shown in table 1 . Women were younger, had started smoking at a later age and had smoked fewer pack-years as compared with men $(p<0.001)$. More women than men were current smokers $(p=0.049$ in subjects with COPD, $p=0.001$ in subjects without COPD). Women were more likely to report a history of asthma than men ( $p \leq 0.001)$, whereas bronchodilator response was only significantly different by gender among those without COPD $(p=0.015)$. More men than women reported occupational exposure to dust or gas $(p<0.001)$. Females with COPD had a lower educational level as compared with males $(p=0.008)$. Lung function or GOLD (Global Initiative for Chronic Obstructive Lung Disease) stage did not differ by gender.

Gender differences were more pronounced in the early-onset and low exposure COPD subgroups (table 2). In the early-onset COPD group, females had lower $\mathrm{FEV}_{1} \%$ predicted $(\mathrm{p}=0.006)$ and a borderline significant trend for more severe COPD $(p=0.050)$ than males. A similar trend was observed in the low exposure group, where females had lower $\mathrm{FEV}_{1} \%$ predicted $(\mathrm{p}=0.001)$ and more severe COPD $(p=0.020)$ than males. Women were more likely to report a history of asthma in both subgroups $(p<0.001)$, whereas men were more likely to report occupational exposure to dust or gas $(p<0.001)$. Women had a more pronounced bronchodilator response in the early-onset group $(p=0.036)$. Age and percentage of current smokers were not significantly different by gender in these subgroups (data not shown).

\section{The association between gender and lung function in subjects with COPD}

The results of multivariate regression analysis of $\mathrm{FEV}_{1} \%$ predicted in subjects with COPD, with gender included as a predictor in the models, are shown in table $3 . \mathrm{FEV}_{1}$ was not affected by gender when analysing all subjects with COPD. However, female gender was associated with $5.7 \%$ lower $\mathrm{FEV}_{1} \%$ predicted in the low exposure group $(p=0.012)$ and there was a similar trend in the early-onset group (table 3 ). There were significant gender $\times$ pack-years interactions in all subjects with COPD $(p=0.027)$ and in the early-onset group $(p=0.014)$, and a borderline significant interaction in the low exposure group $(\mathrm{p}=0.066)$.

Additional analyses were stratified by asthma status (tables E1 and E2 in the online data supplement). For subjects without selfreported asthma history, female gender was associated with lower lung function in the early-onset group. For subjects with self-reported asthma history, on the other hand, female gender was associated with lower lung function in the low exposure group. Significant gender $\times$ smoking interactions were observed in subjects who self-reported asthma history, both in all subjects with COPD and in the early-onset group (table E2).

\section{The association between smoking and lung function in subjects with and without COPD, by gender}

The effects of each pack-year on $\mathrm{FEV}_{1}$ in millilitres and $\mathrm{FEV}_{1} \%$ predicted, by disease status and gender, are presented in table 4. In male subjects with COPD, the reduction in $\mathrm{FEV}_{1}$ per packyear was $5.1 \mathrm{ml}$, corresponding to a $0.15 \%$ reduction of $\mathrm{FEV}_{1} \%$ predicted. Pack-years was not significantly associated with $\mathrm{FEV}_{1}$ in female subjects with COPD. There was a significant 
Table 1 Characteristics of the study subjects by gender, Bergen, Norway 2003-2005

\begin{tabular}{|c|c|c|c|c|c|c|}
\hline & \multicolumn{3}{|c|}{ Subjects with COPD } & \multicolumn{3}{|c|}{ Subjects without COPD } \\
\hline & $\begin{array}{l}\text { Male } \\
n=583(61.1 \%)\end{array}$ & $\begin{array}{l}\text { Female } \\
n=371(38.9 \%)\end{array}$ & $\mathrm{p}$ Value & $\begin{array}{l}\text { Male } \\
\mathrm{n}=479(50.2 \%)\end{array}$ & $\begin{array}{l}\text { Female } \\
n=476(49.8 \%)\end{array}$ & p Value \\
\hline Age, years & $66.2(10.2)$ & $64.4(9.8)$ & 0.009 & $56.3(9.9)$ & $54.8(9.4)$ & 0.013 \\
\hline Ex- & 55.6 & 49.1 & 0.049 & 64.3 & 53.6 & 0.001 \\
\hline Current & 44.4 & 50.9 & & 35.7 & 46.4 & \\
\hline Pack-years, median $\left(25,75^{*}\right)$ & $32.2(22.5,44.9)$ & $24.0(17.2,34.1)$ & $<0.001$ & $18.0(10.5,28.0)$ & $14.2(8.0,23.3)$ & $<0.001$ \\
\hline Bronchodilator response & $7.4(13.1)$ & $8.5(13.6)$ & 0.229 & $3.1(4.0)$ & $3.8(4.5)$ & 0.015 \\
\hline Occupational exposure, \% & 79.4 & 45.5 & $<0.001$ & 66.7 & 32.4 & $<0.001$ \\
\hline \multicolumn{7}{|l|}{ Educational level, \% } \\
\hline Primary & 29.9 & 33.6 & 0.008 & 16.5 & 12.2 & 0.100 \\
\hline Secondary & 56.3 & 59.0 & & 57.1 & 62.8 & \\
\hline \multicolumn{7}{|l|}{ GOLD stage, $\%$} \\
\hline 2 & 55.1 & 55.5 & 0.971 & - & - & \\
\hline 3 & 30.4 & 30.5 & & - & - & \\
\hline 4 & 14.6 & 14.0 & & - & - & \\
\hline
\end{tabular}

Unless otherwise noted, data are presented as means (SD).

*25th and 75 th percentiles.

FEV $_{1}$, forced expiratory volume in $1 \mathrm{~s}$; FVC, forced vital capacity; GOLD, Global Initiative for Chronic Obstructive Lung Disease; post-BD, postbronchodilator.

interaction between gender and pack-years among subjects with COPD ( $\mathrm{p}=0.027$ for $\mathrm{FEV}_{1} \%$ predicted). Among subjects without COPD, the effect of each pack-year on $\mathrm{FEV}_{1} \%$ predicted was greater for women than for men, and no gender $\times$ pack-years interaction was observed.

Analyses that were stratified by self-reported asthma history (tables E3 and E4 in the online data supplement) showed similar results. The differences between men and women were most striking among subjects with COPD with self-reported asthma history, where pack-years was strongly associated with lung function in men but not in women. The gender $\times$ pack-years interaction was only significant in the subjects with COPD with self-reported asthma history. The analyses of some subgroups were probably underpowered and should be interpreted with caution.

Figure 1 illustrates the dose-response relationship between number of pack-years and post-BD $\mathrm{FEV}_{1} \%$ predicted for male and female subjects with COPD in this study. Subjects with $>100$ pack-years were excluded from this illustration (one female and three males). The figure shows a divergence of the curves for male and female subjects with COPD at lower smoking levels, but the curves appear more similar as the level of exposure exceeds 25-30 pack-years. The same relationships were observed when stratifying for self-reported asthma history (figure E1 and figure E2 in the online data supplement). The dose-response relationship for lower levels of exposure was similar in male and female subjects without COPD (figure E3 in the online data supplement).

\section{DISCUSSION}

In a large COPD study, our findings suggested a gender difference in susceptibility to the lung-damaging effects of cigarette smoking. Despite younger age, later age of smoking onset and fewer pack-years, females with COPD had similar lung function

Table 2 Characteristics of subjects with chronic obstructive pulmonary disease (COPD) in the early-onset group and the low exposure group*

\begin{tabular}{|c|c|c|c|c|c|c|}
\hline & \multicolumn{3}{|c|}{ Early-onset group (age <60) } & \multicolumn{3}{|c|}{ Low exposure group (pack-years $<20$ ) } \\
\hline & $\begin{array}{l}\text { Male } \\
n=177(56 \%)\end{array}$ & $\begin{array}{l}\text { Female } \\
n=139(44 \%)\end{array}$ & p Value & $\begin{array}{l}\text { Male } \\
n=118(49 \%)\end{array}$ & $\begin{array}{l}\text { Female } \\
n=123(51 \%)\end{array}$ & p Value \\
\hline Pack-years, median $(25,75 \dagger)$ & $28.4(20.4,39.0)$ & $24.0(17.2,33.2)$ & 0.003 & $15.0(10.0,17.5)$ & $13.1(8.3,17.2)$ & 0.112 \\
\hline Self-reported asthma, \% & 39.6 & 64.5 & $<0.001$ & 44.9 & 70.7 & $<0.001$ \\
\hline Bronchodilator response & $5.8(11.7)$ & $8.8(14.0)$ & 0.036 & $9.8(16.8)$ & $7.5(13.6)$ & 0.235 \\
\hline Occupational exposure, \% & 81.2 & 51.2 & $<0.001$ & 81.0 & 43.9 & $<0.001$ \\
\hline \multicolumn{7}{|l|}{ Educational level, \% } \\
\hline Primary & 22.0 & 21.6 & 0.194 & 33.9 & 33.9 & 0.003 \\
\hline Secondary & 59.3 & 66.9 & & 47.5 & 61.2 & \\
\hline University & 18.6 & 11.5 & & 18.6 & 5.0 & \\
\hline $\mathrm{FEV}_{1} \%$ predicted & $56.0(17.2)$ & $50.6(16.9)$ & 0.006 & $55.8(16.2)$ & $48.7(17.6)$ & 0.001 \\
\hline GOLD 3 or $4, \%$ & 31.1 & 41.7 & 0.050 & 35.6 & 50.4 & 0.020 \\
\hline
\end{tabular}

Unless otherwise noted, data are presented as means (SD).

*88 subjects are present in both groups.

+25 th and 75th percentiles.

FEV $_{1}$, forced expiratory volume in $1 \mathrm{~s}$; GOLD, Global Initiative for Chronic Obstructive Lung Disease. 
Table 3 The association between gender and $\mathrm{FEV}_{1} \%$ predicted in subjects with chronic obstructive pulmonary disease (COPD), with regression coefficients $(\beta)$ and $p$ values for female gender and for the interaction between gender and smoking

\begin{tabular}{|c|c|c|c|c|c|}
\hline & \multirow[b]{2}{*}{$\mathbf{n} \neq$} & \multicolumn{2}{|l|}{ Gender* } & \multicolumn{2}{|c|}{ Gender×pack-years $\dagger$} \\
\hline & & $\overline{\beta(95 \% \mathrm{CI})}$ & $\bar{p}$ Value & $\bar{\beta}(95 \% \mathrm{Cl})$ & p Value \\
\hline $\begin{array}{l}\text { All subjects } \\
\text { with COPD }\end{array}$ & 948 & $-0.2(-2.5$ to 2.1$)$ & 0.865 & $0.2(0.02$ to 0.3$)$ & 0.027 \\
\hline $\begin{array}{l}\text { Early onset, } \\
\text { age }<60\end{array}$ & 315 & $-3.8(-7.6$ to 0.1$)$ & 0.057 & $0.3(0.1$ to 0.6$)$ & 0.014 \\
\hline $\begin{array}{l}\text { Low exposure, } \\
<20 \text { pack-years }\end{array}$ & 239 & $-5.7(-10.2$ to -1.3$)$ & 0.012 & $0.8(-0.1$ to 1.8$)$ & 0.066 \\
\hline
\end{tabular}

*Basic model with no interaction term, adjusted for pack-years, self-reported asthma and educational level.

$\dagger$ Gender $\times$ pack-years interaction terms are included in the basic models.

\#Educational level was missing for five subjects with COPD; asthma history was missing

for one subject with COPD.

$\mathrm{FEV}_{1}$, forced expiratory volume in $1 \mathrm{~s}$.

reduction as males with COPD in the total study sample. In subgroups of subjects with COPD with early-onset disease or low smoking exposure, female gender was associated with lower lung function. Number of pack-years was not significantly associated with lung function in female subjects with COPD in this study, and the dose-response relationship between smoking and lung function differed by gender at lower levels of smoking exposure.

Definitions of 'early-onset' COPD and 'low exposure' of smoking have not been established in guidelines or in the literature. The choice of thresholds of 60 years as 'early onset' and 20 pack-years as 'low exposure' were based partly on existing literature and clinical experience, and partly on methodological concerns. Silverman et al demonstrated a female predominance among early-onset cases $<53$ years of age in the Boston EarlyOnset Study. ${ }^{19}$ In order to have a certain age range (40-60 years) and keep a reasonable number of subjects, we defined early-onset $\mathrm{COPD}$ as $<60$ years in this study. For the same reasons, we chose a threshold of 20 pack-years for the low exposure group. It is worth noting that our results for the low exposure group are still significant with a threshold of 10 pack-years of smoking (data not shown).

The observed gender differences among the early-onset and low exposure subjects suggest that female gender is associated with lower lung function and more severe disease in these COPD subgroups (table 2 and table 3 ). The opposite directions of the main effect and the interaction effect in table 3 may suggest that the gender effect is most pronounced when the level of smoking exposure is low, decreasing in magnitude with an increasing number of pack-years. However, whether these findings reflect that women in general tolerate smoking less well than men, and subsequently experience lung damage at an earlier age or in response to less smoking exposure, is uncertain. Exposure other than smoking exposure, reporting bias or selection bias are other possible explanations for the observed findings in the COPD subgroups.

Number of pack-years was not associated with reduced lung function in female subjects with COPD in our study (table 4). This can be explained by the lack of the expected dose-response relationship in females with COPD in this particular study (figure 1). As the figure shows, females had a more severe reduction of $\mathrm{FEV}_{1}$ for lower levels of exposure but, after 25-30 packyears, the dose-response relationship was more similar to that observed in males. These findings suggest that female smokers may have higher susceptibility to smoking-related lung damage at lower levels of exposure, and that the dose-response relationship may vary by gender. An alternative explanation is that the increased susceptibility in female smokers is unrelated to the number of pack-years, and that another unknown factor is causing lower lung function in female smokers. Even though no never-smokers were included in our study, it is worth noting that female gender has been reported to be a risk factor for COPD in lifetime never-smokers. ${ }^{20}$

Our findings are consistent with several studies demonstrating an increased susceptibility to COPD in female smokers, ${ }^{2-7}$ but in contrast to findings in other studies. ${ }^{8}$ A recent systematic review and meta-analysis of longitudinal studies examining decline in lung function found evidence of a faster decline in female smokers aged $>45-50$ years as compared with male smokers. ${ }^{3}$

Airway disease is influenced by gender-related factors across the human life span, ${ }^{21}$ and both biological and socio-cultural factors should be recognised when discussing gender differences in lung diseases. In families of individuals with severe earlyonset COPD, a female predominance among COPD cases was observed, ${ }^{19}$ possibly representing a genotype $\times$ gender interaction. Women may be biologically more susceptible to the adverse effects of smoking than men, due to sex differences in cigarette smoke metabolism. ${ }^{22}$ The airways of women are anatomically smaller, and each cigarette may represent a proportionally greater exposure. ${ }^{23}$ Dimensional, immunological and hormonal determinants are other biological possibilities for a gender difference. ${ }^{21}$

Table 4 The association between smoking and lung function, with the regression coefficients $(\beta)$ and $p$ values for each pack-year's impact on FEV ${ }_{1}$ $(\mathrm{ml})^{*}$ and $\mathrm{FEV}_{1} \%$ predicted $\dagger$

\begin{tabular}{|c|c|c|c|c|c|c|c|}
\hline & \multirow[b]{2}{*}{$\mathbf{n} \neq$} & \multicolumn{3}{|l|}{$\mathrm{FEV}_{1}(\mathrm{ml})$} & \multicolumn{3}{|l|}{ FEV $_{1}(\%)$} \\
\hline & & $\beta(95 \% \mathrm{CI})$ & p Value & $\mathrm{p}$ (interaction) & $\beta(95 \% \mathrm{Cl})$ & p Value & $\mathbf{p}$ (interaction) \\
\hline \multicolumn{8}{|c|}{ Subjects with COPD } \\
\hline All§ & 948 & $-3.6(-5.6$ to -1.7$)$ & 0.000 & & $-0.11(-0.17$ to -0.04$)$ & 0.001 & \\
\hline Female & 365 & $-0.1(-3.7$ to 3.5$)$ & 0.952 & 0.025 & $0.002(-0.11$ to 0.12$)$ & 0.967 & 0.027 \\
\hline \multicolumn{8}{|c|}{ Subjects without COPD } \\
\hline All§ & 954 & $-3.1(-4.6$ to -1.6$)$ & 0.000 & & $-0.09(-0.13$ to -0.05$)$ & 0.000 & \\
\hline
\end{tabular}

$p$ (interaction) is the $p$ value for the interaction term gender $\times$ pack-years.

*Adjusted for sex, age, height, pack-years, self-reported asthma and educational level.

†Adjusted for sex, pack-years, self-reported asthma and educational level.

¥Educational level was missing for five female subjects with COPD and one of the male subjects without COPD; asthma history was missing for one of the female subjects with COPD.

$\S$ Models without an interaction term.

TModels including a gender $\times$ pack-years interaction term; gender-specific estimates obtained by the lincom command in Stata.

COPD, chronic obstructive pulmonary disease; $\mathrm{FEV}_{1}$, forced expiratory volume in $1 \mathrm{~s}$. 


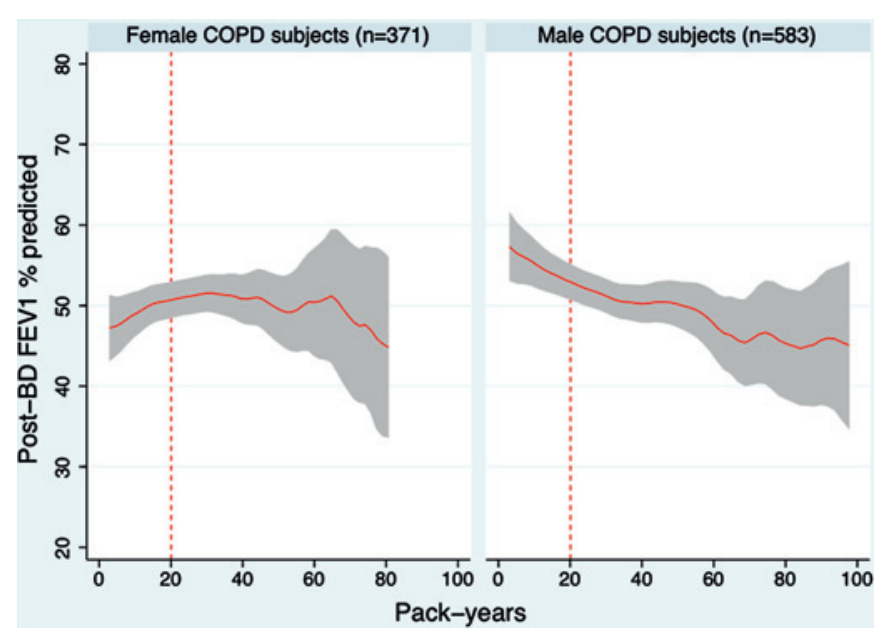

Figure 1 The dose-response relationship between number of packyears and postbronchodilator (post-BD) forced expiratory volume in $1 \mathrm{~s}$ $\left(\mathrm{FEV}_{1}\right) \%$ predicted in male and female subjects with chronic obstructive pulmonary disease (COPD), expressed by a local polynomial smoothed regression line with $95 \% \mathrm{Cl}$.

Alternative explanations for the observed gender difference in our study should also be considered. Could a subgroup of female smokers in our study have asthma with fixed airflow obstruction $^{24}$ rather than COPD? After puberty, the incidence of asthma is higher in women than in men. ${ }^{21}$ More women than men reported a history of asthma in our study; however, the validity of these data is questionable. Many patients in Norway use the terms asthma and COPD interchangeably, maybe especially so back in 2003-2005, when the public awareness of COPD was lower than today. The gender difference in selfreported asthma prevalence could also be due to diagnostic bias, since women are less likely to be diagnosed with COPD than men. ${ }^{25}$ The results of all multivariate analyses are adjusted for self-reported asthma history, and results stratified by asthma status can be found in the online data supplement (tables $\mathrm{E} 1-\mathrm{E} 4$, figures $\mathrm{E} 1$ and $\mathrm{E} 2)$. The results of asthma-stratified analyses were in the same direction as the primary analyses, but some of the analyses were probably underpowered due to the small sample size in the subgroups.

In addition to asthma, possible explanations for the observed gender differences in this study also include occupational exposure, second-hand smoke, inhalation pattern, selection bias and reporting bias. However, work-related exposure to dust or gas was substantially higher in men than in women, and hence cannot explain the observed gender differences. No significant gender difference in exposure to second-hand smoking was observed in this study, and female smokers reported a lesser depth of inhalation than male smokers (data not shown). Given the deviation from the expected dose-response relationship in females with COPD (figure 1), we cannot fully exclude that this could be due to selection bias or some other unmeasured confounder. Finally, it makes sense to speculate whether underreporting smoking consumption among women could explain the observed differences. Although the possibility of reporting bias cannot be excluded, a meta-analysis has found self-reported smoking data to be accurate in most studies. ${ }^{26}$

$\mathrm{FEV}_{1}$ and the spirometry-defined GOLD stages may not fully capture the phenotypic variation that underlies a gender difference in susceptibility to tobacco smoke. Men and women may be phenotypically different in their response to tobacco smoke, with men being more likely to develop an emphysematous phenotype and women more likely to develop an airwaypredominant phenotype. ${ }^{23}$ This hypothesis is supported by recent findings in studies examining gender differences in radiological manifestations observed on CT scans, showing that women have less emphysema but thicker airway walls than men. ${ }^{27}{ }^{28}$ However, when examining quantitative CT data available on approximately half of this particular case-control study population, Grydeland et al found both the percentage emphysema and airway wall thickness to be higher in men than in women. ${ }^{29}$

The limitations of our study should be acknowledged. We are presenting results from a cross-sectional study with lung function measurements from only one time point. Nonetheless, our results were consistent with the results of several prospective longitudinal studies. ${ }^{3}$ Our study sample did not represent a population-based sample, and it is therefore uncertain whether these findings apply to the general population. The way participants were selected for the study could potentially have affected the results, and selection bias cannot be excluded. The fact that no never-smokers were included limits our ability to assess the smoking effect. Furthermore, one could argue that the analyses of $\mathrm{FEV}_{1} \%$ predicted should be interpreted with caution, since the results may be dependent on the prediction equations and the reference population used. ${ }^{15}$ However, when applying a different set of reference values ${ }^{30}$ to test the robustness of our results, all of our main findings were still valid (data not shown).

Our findings demonstrated that the intersections between gender, smoking and lung function are complicated, especially among subjects with COPD. Focusing on subgroups of the study sample may improve our ability to detect gender differences in COPD, but results should be interpreted with caution. We found that female gender was associated with lung function reduction in subgroups of subjects with COPD with early onset of disease or low smoking exposure. Our findings may suggest a gender difference in susceptibility to the lung-damaging effects of cigarette smoking, but alternative explanations should be considered.

Funding Funding sources for the data collection included The Norwegian Research Council, GlaxoSmithKline and The Foundation for Respiratory Research, Haukeland University Hospital, Bergen, Norway. DLD was supported by NIH R01 HL089438 and received support from a Clinical Scientist Development Award from the Doris Duke Foundation.

The funding sources had no role in the data analysis, data interpretation, writing of the report, or in the decision to submit the paper for publication.

Competing interests I-CS received lecture fees from AstraZeneca in 2008, and a travel grant and a lecture fee from GlaxoSmithKline in 2009. EKS received an honorarium for a talk on COPD genetics in 2006, grant support for two studies of COPD genetics, and consulting fees from GlaxoSmithKline. He also received honoraria in 2007 and 2008 and consulting fees from AstraZeneca. All other authors: none.

Ethics approval This case-control study was conducted with the approval of the Regional Committee for Medical Research Ethics (REK Vest), the Norwegian Data Inspectorate and the Norwegian Department of Health.

Provenance and peer review Not commissioned; externally peer reviewed.

\section{REFERENCES}

1. Mannino DM, Homa DM, Akinbami LJ, et al. Chronic obstructive pulmonary disease surveillance-United States, 1971-2000. MMWR Surveill Summ 2002:51:1-16.

2. Chen Y, Horne SL, Dosman JA. Increased susceptibility to lung dysfunction in female smokers. Am Rev Respir Dis 1991;143:1224-30.

3. Gan W0, Man SF, Postma DS, et al. Female smokers beyond the perimenopausal period are at increased risk of chronic obstructive pulmonary disease: a systematic review and meta-analysis. Respir Res 2006;7:52.

4. Langhammer $\mathbf{A}$, Johnsen $\mathrm{R}$, Gulsvik $\mathrm{A}$, et al. Sex differences in lung vulnerability to tobacco smoking. Eur Respir J 2003;21:1017-23.

5. Prescott E, Bjerg AM, Andersen PK, et al. Gender difference in smoking effects on lung function and risk of hospitalization for COPD: results from a Danish longitudinal population study. Eur Respir J 1997;10:822-7. 
6. $\mathbf{X u ~ X , ~ L i ~ B , ~ W a n g ~ L . ~ G e n d e r ~ d i f f e r e n c e ~ i n ~ s m o k i n g ~ e f f e c t s ~ o n ~ a d u l t ~ p u l m o n a r y ~}$ function. Eur Respir J 1994; 7:477-83.

7. $\mathbf{X u} \mathbf{X}$, Weiss ST, Rijcken B, et al. Smoking, changes in smoking habits, and rate of decline in FEV1: new insight into gender differences. Eur Respir J 1994:7:1056-61.

8. $\mathbf{X u} \mathbf{X}$, Dockery DW, Ware JH, et al. Effects of cigarette smoking on rate of loss of pulmonary function in adults: a longitudinal assessment. Am Rev Respir Dis 1992;146:1345-8.

9. DeMeo DL. The Yin and Yang of COPD: sex/gender differences in the National Emphysema Treatment Trial. Am J Respir Crit Care Med 2007:176:222-3.

10. Soerheim IC, Johannessen A, Bakke P, et al. Gender differences in COPD - are women more susceptible to smoking effects? Am J Respir Crit Care Med 2009;179:A3750

11. Sørheim IC, Johannessen A, Grydeland TB, et al. Case-control studies on risk factors for COPD: how does the sampling of the cases and controls affect the results? Clin Respir J 2009. doi:10.1111/j.1752-699X.2009.00154.x.

12. Bakke $\mathbf{P}$, Gulsvik A, Lilleng $\mathrm{P}$, et al. Postal survey on airborne occupational exposure and respiratory disorders in Norway: causes and consequences of non-response. J Epidemiol Community Health 1990:44:316-20.

13. Brogger J, Bakke P, Eide GE, et al. Contribution of follow-up of nonresponders to prevalence and risk estimates: a Norwegian respiratory health survey. $A m \mathrm{~J}$ Epidemiol 2003:157:558-66.

14. Anon. Standardization of spirometry, 1994 update. American Thoracic Society. Am J Respir Crit Care Med 1995:152:1107-36.

15. Gulsvik A, Tosteson T, Bakke P, et al. Expiratory and inspiratory forced vital capacity and one-second forced volume in asymptomatic never-smokers in Norway. Clin Physiol 2001;21:648-60.

16. Johannessen A, Omenaas ER, Bakke PS, et al. Implications of reversibility testing on prevalence and risk factors for chronic obstructive pulmonary disease: a community study. Thorax 2005; 60:842-7.

17. Bakke PS, Hanoa R, Gulsvik A. Educational level and obstructive lung disease given smoking habits and occupational airborne exposure: a Norwegian community study. Am J Epidemiol 1995:141:1080-8.
18. Prescott E, Godtfredsen N, Vestbo J, et al. Social position and mortality from respiratory diseases in males and females. Eur Respir $\mathrm{J}$ 2003;21:821-6.

19. Silverman EK, Weiss ST, Drazen JM, et al. Gender-related differences in severe, early-onset chronic obstructive pulmonary disease. Am J Respir Crit Care Med 2000;162:2152-8.

20. Whittemore AS, Perlin SA, DiCiccio Y. Chronic obstructive pulmonary disease in lifelong nonsmokers: results from NHANES. Am J Public Health 1995;85:702-6.

21. Becklake MR, Kauffmann F. Gender differences in airway behaviour over the human life span. Thorax 1999:54:1119-38.

22. Ben-Zaken Cohen S, Pare PD, Man SF, et al. The growing burden of chronic obstructive pulmonary disease and lung cancer in women: examining sex differences in cigarette smoke metabolism. Am J Respir Crit Care Med 2007:176:113-20.

23. Han MK, Postma D, Mannino DM, et al. Gender and chronic obstructive pulmonary disease: why it matters. Am J Respir Crit Care Med 2007;176:1179-84.

24. Fabbri LM, Romagnoli M, Corbetta L, et al. Differences in airway inflammation in patients with fixed aiflow obstruction due to asthma or chronic obstructive pulmonary disease. Am J Respir Crit Care Med 2003:167:418-24.

25. Chapman KR, Tashkin DP, Pye DJ. Gender bias in the diagnosis of COPD. Chest 2001;119:1691-5.

26. Patrick DL, Cheadle A, Thompson DC, et al. The validity of self-reported smoking: a review and meta-analysis. Am J Public Health 1994;84:1086-93.

27. Dransfield MT, Washko GR, Foreman MG, et al. Gender differences in the severity of CT emphysema in COPD. Chest 2007:132:464-70.

28. Martinez FJ, Curtis JL, Sciurba F, et al. Sex differences in severe pulmonary emphysema. Am J Respir Crit Care Med 2007;176:243-52.

29. Grydeland TB, Dirksen A, Coxson HO, et al. Quantitative computed tomography: emphysema and airway wall thickness by sex, age and smoking. Eur Respir $J$ 2009:34:858-65

30. Johannessen A, Lehmann S, Omenaas ER, et al. Post-bronchodilator spirometry reference values in adults and implications for disease management. Am J Respir Crit Care Med 2006;173:1316-25.

\section{Lung alert}

\section{IL-23 and allergic airway inflammation}

This study examines the role of interleukin 23 (IL-23) in airway inflammation in asthma, focusing on the ability of IL-23 to promote inflammation independently of the known IL-17 pathway and via its effect on T helper 2 (Th2) polarisation. These interactions are studied using in vitro and in vivo techniques.

Mice exposed to allergen showed a significant increase in IL-23-specific p19 mRNA and IL23 receptor mRNA. In mice induced to overexpress IL-23, an increased inflammatory cell infiltrate was observed after allergen challenge. In IL-23 knockout mice, exposure to the same allergen challenge resulted in a significant reduction in airway inflammation.

Having established a role for IL-23 in airway inflammation the authors next examined its signalling pathway. No significant alteration in IL-17 expression was seen between the IL-23 knockout and IL-23-expressing mice, thus suggesting a possible pathway independent of IL17. In contrast, the levels of Th2 cytokines (IL-4, IL-5 and IL-13) were seen to vary significantly between the two groups. In the knockout mice, a dramatic reduction in Th2 cytokines was observed in lymphatic cultures.

Further examination of this pathway in vitro used CD4 $\mathrm{T}$ cells activated via an antigenpresenting cell-dependent or -independent mechanism. In both cases IL-23 affected Th2 differentiation. Partial Th2 inhibition was seen in the absence of IL-23 and increasing differentiation was observed in the IL-23-positive cell line.

This study confirms the importance of IL-23 and its receptor in regulating airway inflammation and identifies a possible signalling pathway between IL-23 and Th2 cells independent of IL-17.

Peng J, Yang XO, Tesfaigzi Y, Chang SH et al. IL-23 signalling enhances Th2 polarization and regulates allergic airway inflammation, lung function, and COPD in high-risk populations. Cell Res 2010;20:62-71.

\section{Charlotte Addy}

Correspondence to Charlotte Addy, ST4, Bristol Royal Infirmary, UK; chill1981@doctors.org.uk

Thorax 2010;65:485. doi:10.1136/thx.2010.141101 